\title{
Determination of the Optical Properties of Bovine Liver Tissue Using Integrating Sphere Technique
}

\author{
*Halil Arslan and Yasar Baris Dolukan \\ Faculty of Technology, Electrical and Electronics Engineering Department, \\ Sakarya University of Applied Sciences, Turkey
}

\begin{abstract}
The optical properties (absorption and reduced scattering coefficients, $\mu_{\mathrm{a}}$ and $\mu_{\mathrm{s}}$ ') of bovine liver tissue for $635 \mathrm{~nm}$ have been determined by using integrating sphere and inverse adding-doubling (IAD) techniques. For this purpose, total reflectance and total transmittance values of bovine liver tissue sample, which is placed between two microscope slides, have been measured by using single-sphere system. The measured values have been used as input parameters for IAD program to extract the $\mu_{\mathrm{a}}$ and $\mu_{\mathrm{s}}^{\prime}$ of the sample. In this study, $\mu_{\mathrm{a}}$ and $\mu_{\mathrm{s}}$ ' of bovine liver tissue for $635 \mathrm{~nm}$ have been determined to be $0.22 \mathrm{~mm}^{-1}$ and $0.51 \mathrm{~mm}^{-1}$, respectively. These values, which yield $1.44 \mathrm{~mm}$ penetration depth, are in good agreement with the ones in the literature.
\end{abstract}

Key words: Optical properties, Liver tissue, Integrating sphere.

\section{Introduction}

Estimation of the optical energy received by the biological tissues is necessary for a successful treatment in medical applications. This fact makes the precise determination of the optical properties of the tissues very important [1]. When the light enters the tissue, it is either scattered or absorbed depending both wavelength of the light and the optical characteristics of the tissue. The optical properties are described in terms of various parameters including absorption coefficient $\left(\mu_{a}\right)$, the scattering coefficient $\left(\mu_{s}\right)$, the scattering anisotropy factor $(g)$ and refractive index $(n)$. Absorption and scattering coefficients are defined as the probability of a photon being absorbed and scattered per unit length, respectively [2]. Anisotropy factor is defined as the mean cosine of deflection angle due to a scattering event. In order to describe the combined effect of scattering coefficient and average scattering angle, reduced scattering coefficient $\left(\mu_{s}^{\prime}\right)$ is used. With the help of the reduced scattering coefficient that is calculated by

$\mu_{s}^{\prime}=\mu_{s}(1-g)$,

the scattering property in an environment is fully expressed [3]. Since refractive indices of different kinds of the tissues have very closed values, it is rarely listed in the literature as an optical property. For example, it is known that the refractive indices of the soft tissues have values between 1.38 and $1.42[4]$.

*Corresponding author: Address: Faculty of Technology, Electrical and Electronics Engineering Department, Sakarya University, 54187, Sakarya TURKEY. E-mail address: harslan@sakarya.edu.tr, Phone: +902642957292 
In order to obtain the optical properties of the tissues, measurement results can be analyzed by using different methods such as inverse Monte Carlo modelling and inverse Adding Doubling (IAD) methods. Although inverse Monte Carlo modelling allows to determine the light reflectance, transmittance and fluence rate values, it has several disadvantages such as the need for too much time and being a statistical method [5]. In addition, IAD is one of the general, numerical solution of the radiative transport equation. In this method, the optical properties are obtained by iterating an adding doubling solution of the radiative transport equation until the calculated values match the measured ones [6]. In order to obtain absorption and reduced scattering coefficients by using IAD method, some parameters such as total reflectance and total transmittance need to be known. These parameters are usually measured with integrating sphere system.

In this study, the optical properties $\left(\mu_{a}, \mu_{s}{ }^{\prime}\right)$ of bovine liver tissue for $635 \mathrm{~nm}$ have been determined by using integrating sphere and inverse adding-doubling (IAD) techniques.

\section{Materials and Method}

The experimental setup that is used in this study in order to determine the total reflectance and total transmittance is shown in Figure 1.

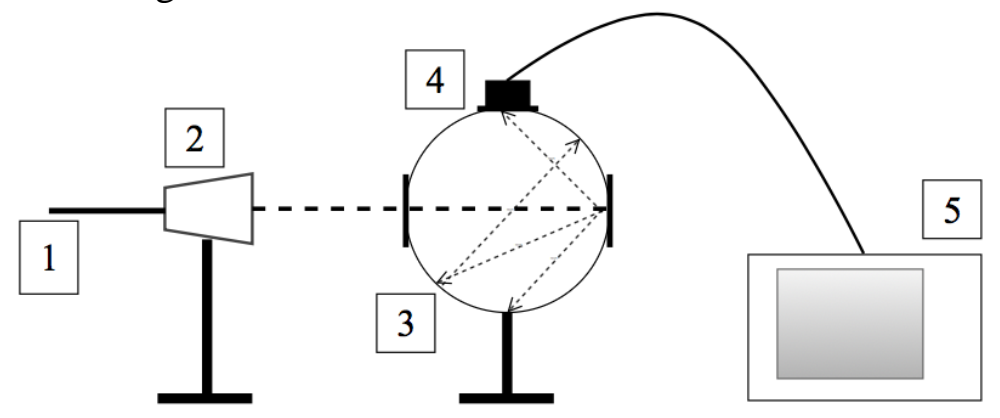

Figure 1. Experimental setup; 1) Fiber optic cable 2) Collimator 3) Integrated sphere 4) $\mathrm{Si}$ photodiode 5) Photodiode amplifier

PDT laser system used in this study produces a constant optical wavelength of $635 \mathrm{~nm}$. Although the device can operate in three different radiation modes (continuous, pulse and burst pulse) [7], only the continuous mode has been used during the experiment. To obtain a parallel light beam, the device is connected to a collimator using a fiber optic cable. The sphere in the system has an inner surface with high reflectivity and low absorption. This property enables to collect the majority of reflected or transmitted lights by the photodiode mounted on it. In addition to Si photodiode, a photodiode amplifier has been used in the experiment in order to convert the photodiode's small output current to a measurable level.

The experiments have been performed by using bovine liver tissue. After raw tissue has been kept at room temperature to ensure thermal equilibrium, a piece of tissue with $0.8 \mathrm{~mm}$ thickness has 
been taken with a scalpel. The sample has been placed between two microscope slides in order to make it suitable for the experiment. The results are discussed in the following section.

\section{Results and Discussion}

When using the IAD software to obtain absorption and reduced scattering coefficients based, total transmittance $\left(M_{T}\right)$, total reflectance $\left(M_{R}\right)$ values are required. In order to determine the $M_{T}$ and $M_{R}$ values, the results of 6 different measurements, which are performed by using the integrated sphere system, are needed.

3 of the measurements are performed for $M_{T}$. Dark background measurement $\left(T_{\text {block }}\right)$ is made by shutting down all the ports of the integrated sphere. The measured value after the port on the side where the light comes from is opened is called $T_{0}$. Then, by placing the tissue sample in front of the open port, transmittance value of the sample $\left(T_{\text {sample }}\right)$ is measured. Finally, $M_{T}$ value is calculated by using these measurement results and the equation;

$M_{T}=\frac{\left(T_{\text {sample }}-T_{\text {block }}\right)}{\left(T_{0}-T_{\text {block }}\right)}$

Similar to the $M_{T}, 3$ different measurements are made for $M_{R}$. In addition to the port on the side where the light comes from, the port at the opposite side is opened. Measured value for this case is recorded as $R_{0} . R_{\text {std }}$ and $R_{\text {sample }}$ have been measured by replacing a standard reflector (99\%) and tissue sample next to the second port, respectively. Then, $M_{R}$ value has been calculated by using the equation;

$M_{R}=r_{s t d} \frac{\left(R_{\text {sample }}-R_{0}\right)}{\left(R_{s t d}-R_{0}\right)}$

where $\mathrm{r}_{\text {std }}$ value has been accepted to be 0.99 . In addition to $M_{R}$ and $M_{T}$ values, some other quantities such as port diameter, tissue thickness and refractive index are used as the input parameters for the IAD software in order to obtain the optical parameters.

In this study, absorption and reduced scattering coefficients of bovine liver tissue have been determined to be $0.22 \mathrm{~mm}^{-1}$ and $0.51 \mathrm{~mm}^{-1}$, respectively. These values are quite compatible with the experimental results available in the literature. Absorption and reduced scattering coefficients of different kinds of liver tissues, together with the optical penetration depth, from various experiments are given in Table 1. 
Table 1. Absorption and reduced scattering coefficients of liver tissues

\begin{tabular}{ccccc}
\hline & $\mu_{\mathrm{a}}\left(\mathrm{mm}^{-1}\right)$ & $\mu_{\mathrm{s}}{ }^{\prime}\left(\mathrm{mm}^{-1}\right)$ & $\delta(\mathrm{mm})$ & Ref. \\
\hline Rat & 0.22 & 0.88 & - & {$[8]$} \\
Rat & 0.65 & 0.71 & - & {$[9]$} \\
Porcine & 0.65 & 0.73 & - & {$[8]$} \\
Goat & 1.23 & 0.98 & - & {$[8]$} \\
Human & 0.23 & 10.02 & - & {$[10]$} \\
Bovine & 0.32 & 0.52 & - & {$[11]$} \\
Bovine & 0.27 & 0.52 & - & {$[12]$} \\
Bovine & - & - & 1.67 & {$[13]$} \\
\hline This Study & 0.22 & 0.51 & 1.44 & \\
\hline
\end{tabular}

According to the diffusion approximation, the optical penetration depth $(\delta)$ can be calculated by using the absorption and reduced scattering coefficients according to the equation of;

$\delta=1 / \sqrt{3 \cdot \mu_{a}\left(\mu_{a}+\mu_{s}^{\prime}\right)}$

The optical parameters estimated in this study gives that the optical penetration depth in bovine liver tissue is $1.44 \mathrm{~mm}$ for $635 \mathrm{~nm}$ wavelength. This result agree with the one from our previous study [13], in which the measurement results was analyzed by using Beer-Lambert law.

\section{Acknowledgements}

This study has been supported by the Sakarya University Scientific Research Project Coordination Department (project number 2017-09-00-013), and TÜBITTAK 1005 project number 116F119.

\section{References}

[1] M. A. Ansari, The effects of tissue optical parameters and interface reflectivity on light diffusion in biological tissues, World Academy of Science, Engineering and Technology, vol. 12 no. 5 pp. 2061-2064, 2011

[2] G. Keiser, Biophotonics concepts to application. $1^{\text {st }}$ ed. Singapore,2016

[3] V. Tuchin,Tissue optics Light scattering methods and instruments for medical diagnosis, $2^{\text {nd }}$ ed.,Washington USA,2007

[4] S. Thompson, Photodynamic therapy utilizing interstitial light delivery combined with spectroscopic methods, $\mathrm{PhD}$ thesis, Lund University,2004

[5] N. Yavari, Optical spectroscopy for tissue diagnostics and treatment control,Ph.D thesis, University of Bergen,2006

[6] S. A. Pharl, M.J. C. van Gemert, A.J. Welch, Determining the optical properties of turbid media by using the adding-doubling method, Apply. Optics , vol.32 no.4 pp.559-568, 1993

[7] H. S. Lim, Reduction of thermal damage in photodynamic therapy by laser irradiation techniques, Journal of Biomedical Optics, 17(12),128001-9,2012 
[8] D.A.Boas, C. Pitris, N. Ramanujam, Handbook of Biomedical Optics, ${ }^{\text {st }}$ ed.,USA ,2016

[9] P. Parsa, S. L. Jacques, N. S. Nishioka, Optical Properties of rat liver between 350 and 2200 nm, Appl. Opt., vol.28 pp.2311-2317,1989

[10] R. Marchesini,A. Bertoni, S. Andreola, E. Melloni, A. E. Sichirollo, Extinction and absorption coefficients and scattering phase function of human tissues in vitro, Appl. Opt., vol. 28 pp.2318-2324, 1989

[11] J. L. Karagiannes, Z. Zhang, B. Grossweiner, L. I. Groosweiner, Applications of the 1-D diffusion approximation to the optics of tissue and tissue phantoms, Appl. Opt., vol.28 pp. 2311-2317,1989

[12] A. Kienle, L. Lilge, M. S. Patterson, R. Hibst, R. Steiner, B. C. Wilson, Spatially resolve absolute diffuse reflectance measurements for noninvasive determination of the optical scattering and absorption coefficients of biological tissue, Appl. Opt., Vol.35 pp. 2304-2314, 1996

[13] Y. B. Doluğan, A.N. Ay, H. Arslan, Measurement of the optical penetration depth in calfliver tissue at $635 \mathrm{~nm}$, Turkish physical society $33^{\text {rd }}$ international physics congress, pp. 434, 2017 